\title{
Neurological Deficits in the Presence of the Sinking Skin Flap following Decompressive Craniectomy
}

\author{
Akira Yamaura and Hiroyasu Makino \\ Department of Neurological Surgery \\ Chiba University School of Medicine \\ Inohana-cho, Chiba, Japan
}

\begin{abstract}
Summary
It has been our observation that in the presence of concave deformity of the skin flap following large decompressive craniectomy, unexpected neurological deterioation would occur independently of the primary disease or natural improvement would be unduly impaired, and that such unfavorable phenomena were reversed by cranioplasty. In order to know the true incidence and the nature of this phenomenon, 33 consecutive cases were analyzed. Nine of 30 patients $(30 \%)$ with flat or sinking skin flap showed prompt improvement following cranioplasty. The best 'candidates' for maximum benefit of cranioplasty were those with moderate grade neurological deficits in addition to the presence of concave deformity of skin flap (successful rate of $88 \% ; 7$ among 8 patients). Other factors influencing the results were primary disease (favorable to meningioma), time elapse from the decompressive craniectomy, presence of shunt system, CSF pressure and EEG changes before and after cranioplasty. EEG changes had well coincided with clinical course.

The characteristic phenomenon would be described as "the syndrome of the sinking skin flap," considering that neurological deterioration may be due solely to effect of concave deformity of the skin flap upon the underlying brain tissue.
\end{abstract}

Key words: sinking skin flap, decompressive craniectomy, cranioplasty, CSF pressure

\section{Introduction}

A large decompressive craniectomy would be a life saving procedure in a critical situation with massive cerebral edema, where all available conservative treatments had failed to control raised intracranial pressure. Following craniectomy, the initially tense skin flap becomes gradually relaxed and eventually begins to sink in weeks or months. And some of them would show marked concavity of the skin flap, providing that they are not complicated with secondary hydrocephalus or that this has been well controlled by a shunt system.

It has been our belief that concave deformity of the skin flap potentially causes cerebral dysfunction in the craniectomized area and that correction of such deformity by cranioplasty will improve the disturbed cerebral function. Our first observation ${ }^{73}$ of this rather unusual phenomenon goes back to 1969 , when a 48-yearold man experienced neurological deterioration with concavity of the skin flap on two occasions and these neurological deficits were dramatically improved by cranioplasties. Following this experience, similar episodes in four more cases were reported in retrospective analysis of a large series of cranioplasty following decompressive craniectomy. ${ }^{91}$

During the last 2 years at Chiba University Hospital, 33 such consecutive cases were evaluated carefully before and after cranioplasty, not only with respect to neurological status, but also by electroencephalography (EEG) and cerebrospinal fluid (CSF) pressure in order to learn the true incidence and the nature of the phenomenon. 


\section{Material and Method}

Thirty three consecutive cases with large cranial defects following decompressive craniectomy, admitted for cranioplasty in the period of 2 years commencing January 1975 , were analyzed. All patients underwent unilateral or bilateral craniectomy $1 \frac{1}{2}$ to 18 months (mean: 8.4 months) previously for raised intracranial pressure due to various conditions-intracranial tumor in 13 , cerebrovascular disease in 10 , cerebral contusion in 8, and brain abscess in 2 . Cranioplasty for depressed fracture of any large size was excluded from this series. A shunt system had been placed in 10 of them. Age distribution was from 5 to 69 years (mean: 40 years) with a sex ratio of 19 male and 14 female.

Cranioplasty was performed with a simplified technique; an artificial bone flap was made of rapidly polymerizing methylmetacrylate so as to reform the normal curvature of the vault and this was placed over the temporal fascia-muscledura mater complex, without dissecting such structures to expose the dura mater, in an attempt to prevent undue intradural involvement or complication of postoperative CSF collection. Detailed neurological examination was carried out before and after cranioplasty and repeated until discharge, with pre- and postoperative EEG studies and CSF pressure measurement by lumbar puncture. Subjective improvement of the patient, which could not be confirmed by objective findings, was not included in the considerations.

\section{Results}

a. Neurological improvement after correction of the skin flap deformity by cranioplasty

Preoperative condition of the skin flap was classified into 4 types; 'sinking,' 'flat,' 'full' and 'bulging' (Table 1) and neurological status before cranioplasty into 5 grades (Table 2); 'normal,' 'minimal' (with only minimal deficits which would be detected only in detailed examination; many of the patients had returned to normal life), 'moderate' (with unequivocal deficits but capable of self-care), 'severe' (incapable of self-care because of dense hemiplegia, aphasia or other abnormalities), and 'vegetative.' Neurological tutus before cranioplasty was judged normal in 4 and abnormal in 29 patients.

Neurological improvement after cranioplasty was observed in 9 among all 29 abnormal patients $(30 \%)$ or in 9 among 26 abnormal patients with sinking or flat skin flap (35\%) (Table 2). It is interesting to see such improvement concentrated in cases of moderate neurological deficits with sinking or flat skin flap ( 7 among 8 patients $(88 \%))$. In each group of minimal deficits ( 8 patients) or of severe deficits ( 9 patients), only 1 patient showed improvement. Even in the presence of the sinking skin flap, noen of 2 vegetatives showed any detectable improvement. There was no specific tendency in age distribution. In this series, the number of patients with full or bulging skin flap is too small to be reasonably compared with those with

Table 1 Classification of the preoperative condition of the skin flap.
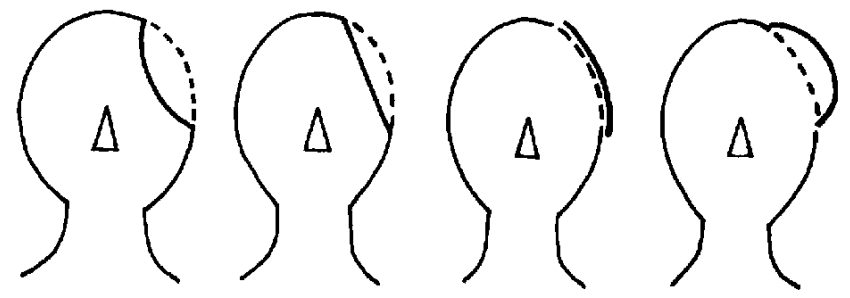

\begin{tabular}{cccccc}
\hline $\begin{array}{c}\text { Neurological } \\
\text { deficit }\end{array}$ & Sinking & Flat & Full & Bulging & Total \\
\hline present & 21 & 5 & 1 & 2 & 29 \\
absent & 4 & & & & 4 \\
& 25 & 5 & 1 & 2 & 33 \\
\hline
\end{tabular}


Table 2 Neurological changes following cranioplasty in relation to the preoperative condition of the skin flap and to grades of neurological deficits.

\begin{tabular}{|c|c|c|c|c|c|}
\hline \multirow{2}{*}{$\begin{array}{l}\text { Shape of } \\
\text { Skin flap }\end{array}$} & \multicolumn{5}{|c|}{ Neurological deficit } \\
\hline & Normal & Minimal & Moderate & Severe & Vegetative \\
\hline sinking & $\begin{array}{l}0 \\
0^{*} \\
0 \\
0\end{array}$ & $\begin{array}{l}0 \\
0 \\
0 \\
0 \\
0\end{array}$ & & $\begin{array}{cc}\bigcirc & 0 \\
\bigcirc & \bigcirc \\
\bigcirc & \bigcirc^{*}\end{array}$ & $\bigcirc^{*}$ \\
\hline flat & & 0 & $\bigcirc$ & $\bigcirc$ & \\
\hline full & & 0 & & & \\
\hline bulging & & 0 & & $\bigcirc^{*}$ & \\
\hline total & 4 & 9 & 8 & 10 & 2 \\
\hline
\end{tabular}

sinking skin flap; the greatest chance of improvement, however, would be expected in those with moderate neurological deficits and with skin flap of the sinking or flat type, and less possibility in those with minimal or severe neurological deficits, especially in the light of our previous analysis. ${ }^{9)}$ Accordingly, 'candidates' for maximum benefit of cranial repair by cranioplasty would be defined as patients with 'sinking' or 'flat' skin flap and with neurological deficits of 'moderate' grade.

Table 3 shows the effects of cranioplasty on neurological status in relation to the primary disease. Meningioma was the largest in number, occupying one third in this series and had the greatest chance of improvement as seen in 6 out of 11 patients $(55 \%)$. Among 6 aneurysms and 8 trauma cases, there was only one patient in each category who showed neurological improvement. However, it is not clear whether this favorable trend in meningioma is due to the nature of the primary disease or due to the incidental frequency of 'candidate' patients.

Time elapse from the decompressive craniectomy to the cranioplasty was $1 \frac{1}{2}$ to 18 months mean 8.4 months). Unreasonable delay of the cranial repair would be considered to give longer exposure to the risk of concave deformity of the intracranial structure under the sinking skin flap. Mean time elapse was 9.8 months in patients who responded with neurological improvement to the cranial repair, in contrast with 7.8 months in those with no improvement. However, this difference fell outside the area of statistical significance.

As for the 9 patients with a shunt system, as indicated in Table 2, the skin flap was sinking in 8 with previous shunt system but it was bulging in one who underwent shunting for hydrocephalus and cranioplasty simultaneously. Neurological improvement was seen in 3 out of 7 patients with shunt system (43\%) with neurological 21 comparable patients $(29 \%)$ without shunt system.

\section{b. Measurement of CSF pressure}

Opening pressure was recorded on lumbar puncture, performed in lateral position with the craniectomized side up, before and after cranioplasty in 10 patients and in 5 other patients only before the procedure; in 2 of the latter, puncture was unsuccessful even though performed by the well-experienced operatives (Table 4). With only one exception, preoperative CSF pressure was below the level of $80 \mathrm{mmH}_{2} \mathrm{O}$, including 4 studies which showed CSF pressure 
Table 3 Neurological changes following cranioplasty in relation to the primary disease and to grades of neurological deficits.

\begin{tabular}{|c|c|c|c|c|c|}
\hline \multirow{2}{*}{$\begin{array}{l}\text { Primary } \\
\text { Disease }\end{array}$} & \multicolumn{5}{|c|}{ Neurological Deficit } \\
\hline & Normal & Minimal & Moderate & Severe & Vegetative \\
\hline \multicolumn{6}{|l|}{$\begin{array}{l}\text { TUMOR } \\
\text { meningioma }\end{array}$} \\
\hline $\begin{array}{l}\text { craniophary- } \\
\text { gioma }\end{array}$ & $O^{*}$ & & & & \\
\hline \multicolumn{6}{|l|}{$\begin{array}{l}\text { oligodendro- } \\
\text { glioma }\end{array}$} \\
\hline \multicolumn{6}{|l|}{$\begin{array}{l}\text { VASCULAR } \\
\text { aneurysm }\end{array}$} \\
\hline $\begin{array}{l}\text { intracebral } \\
\text { hematoma }\end{array}$ & & & & & \\
\hline AVM & & $\bigcirc$ & & 0 & \\
\hline$T R A U M A$ & & & & & $\bigcirc^{*}$ \\
\hline$A B S C E S S$ & $O$ & 0 & & & \\
\hline total & 4 & 9 & 8 & 10 & 2 \\
\hline
\end{tabular}

lower than that of the atmosphere. The two unsuccessful taps might be due to very low CSF pressure or obstruction of the lumbar subarachnoid space. Although it is not rare, in practice, to observe very low CSF pressure in patients with a shunt system, 8 out of 9 craniectomized patients in this series showed low pressure even without a shunt system. All of 3 patients with neurological improvement following correction of the skin flap deformity showed elevation of CSF pressure to normal level. In 4 out of 6 patients whose neurological status remained unchanged in poor condition, CSF pressure remained below the normal limits and total protein was high in most of them. Exceptions were case 7 and case 30 in Table 4, who failed to show prompt neurological improvement in spite of upward CSF pressure changes. Case 7, a 63year-old male, showed only gradual improvement in his right hemiparesis and aphasia subsequent to cranial repair performed 3 months after primary surgery for severe head injury but eventually returned to useful life with normal speech. Case 30 remained disabled, probably because of his advanced age of 69 years and severe primary brain damage from trauma.

\section{c. Electroencephalographic study}

Electroencephalographic study was conducted within 2 weeks before and after cranial repair. Analyzed here are 20 pairs of EEG in patients who had neurological deficits of more than minimal grade and whose skin flap was sinking or flat. Preoperative EEG was abnormal 
Table 4 Measurement of CSF pressure by lumbar puncture before and after cranioplasty.

The reference point is at the level of puncture site in the lateral position.

\begin{tabular}{|c|c|c|c|c|c|c|c|c|}
\hline \multirow{3}{*}{$\begin{array}{l}\text { Casc } \\
\text { No. }\end{array}$} & \multirow{3}{*}{$\begin{array}{l}\text { Primary } \\
\text { Disease }\end{array}$} & \multirow{3}{*}{$\begin{array}{l}\text { Skin } \\
\text { Flap }\end{array}$} & \multicolumn{4}{|c|}{ Lumbar Puncture } & \multirow{2}{*}{\multicolumn{2}{|c|}{ Neurological }} \\
\hline & & & \multicolumn{3}{|c|}{$\begin{array}{l}\text { Opening Pressure } \\
\left(\mathrm{mmH}_{2} \mathrm{O}\right)\end{array}$} & $\begin{array}{r}\text { Protein } \\
\left(\mathrm{mg}^{\mathrm{O}} \%\right)\end{array}$ & & \\
\hline & & & Before & After & Before & After & Before & Improvement \\
\hline 3 & trauma & flat & unsuccessful & & & & minimal & - \\
\hline 7 & trauma & sinking & minus & 80 & & 65 & severe & - \\
\hline $8^{*}$ & trauma & sinking & minus & -150 & & 800 & vegetative & - \\
\hline 9 & $\begin{array}{l}\text { intracerebral } \\
\text { hematoma }\end{array}$ & flat & 80 & 75 & 96 & 95 & severe & - \\
\hline 10 & AVM & sinking & unsuccessful & & & & severe & - \\
\hline 11 & trauma & sinking & 150 & & 24 & & minimal & - \\
\hline 17 & meningioma & sinking & 70 & & 29 & & minimal & + \\
\hline 19 & aneurysm & sinking & 50 & 110 & 24 & 20 & moderate & + \\
\hline $25^{*}$ & meningioma & sinking & minus & 60 & 264 & & moderate & + \\
\hline $26^{*}$ & meningioma & bulging & 80 & 75 & 87 & 127 & severe & - \\
\hline $27^{*}$ & trauma & sinking & 50 & 50 & 140 & 41 & severe & - \\
\hline 29 & trauma & sinking & 55 & 170 & 30 & 50 & severe & + \\
\hline 30 & trauma & sinking & 80 & 200 & 65 & 60 & severe & - \\
\hline 31 & trauma & sinking & minus & & 55 & & severe & - \\
\hline 33 & $\begin{array}{l}\text { intracerebral } \\
\text { hematoma }\end{array}$ & sinking & 0 & 140 & 170 & 62 & severe & - \\
\hline
\end{tabular}

*---shunting procedure

Table 5 EEG and neurological changes following cranioplasty.

\begin{tabular}{lccr}
\hline & \multicolumn{2}{c}{ Neurologically } & \\
\cline { 2 - 3 } $\begin{array}{l}\text { EEG Changes Following } \\
\text { Cranioplasty }\end{array}$ & Improved & No Changes & \\
\hline improved & 6 & 6 & 12 \\
no changes & 1 & 4 & 5 \\
deteriorated & 1 & & 1 \\
equivocal & 1 & 1 & 2 \\
& 9 & 11 & 20 \\
\hline
\end{tabular}

Not including patients with normal neurological status.

All patients with sinking or flat skin flap.

in all but one pair, which was normal before and alter cranioplasty. Improvement of EEG was of a surprising degree, being observed in as many as 12 out of 20 patients $(60 \%)$ (Table 5$)$. Six of those 12 patients $(50 \%)$ with improved EEG and only one among 5 patients $(20 \%)$ with unchanged EEG showed prompt clinical improvement in their neurological status after cranio- plasty. The greatest possibility of clinical improvement would be expected in those whose EEG showed improvement after cranial repair. Among 5 patients with unchanged EEG, 4 were vegetative or disabled with severe neurological deficits.

The most striking improvement in EEG was that of paroxysmal abnormalities. Dys- 
rhythmias, slow abnormalities and lazy activities also showed significant improvement (Table 6). However, low voltage slow abnormality in 2 vegetatives remained unchanged after cranioplasty with their stational grave clinical picture.

Only one exception here is a 23-year-old male, who had undergone bilateral craniectomy and shunt procedure for intraventricular extension of oligodendroglioma, but who showed definite improvement in his left hemiparesis within 2 days after the cranioplasty. However, EEG at the 12th day after cranial repair showed mild progression of slow activities from $6 \mathrm{~Hz}$ to 5 to $6 \mathrm{~Hz}$ over the right hemisphere. No further study was carried out.

\section{d. Presentation of cases}

Case 17: 31-year-old female. Primary disease: right frontal convexity meninigioma

On Apr. 15, 1975, a convexity meningioma was totally removed under surgical microscope and the bone flap was discarded for possible postoperative cerebral edema. Post-operative course was uneventful and she was discharged with only minimal weakness of the left arm. With the onset of marked concavity over the craniectomized area, she noticed progressive clumsiness in her left hand fingers. Cranial repair was immediately undertaken and her clumsiness cleared up promptly. Preoperative lumbar puncture showed opening pressure of $70 \mathrm{mmH}_{2} \mathrm{O}$ with total protein of $29 \mathrm{mg} \%$ (Table 4). EEG on July 26, 1975 (Fig. 1a), showed fairly well ordered alpha activity of $10 \mathrm{~Hz}$. This back- ground activity deteriorated into 7 to $8 \mathrm{~Hz}$ on Nov. 5, 1975 (Fig. 1b), when the skin flap began to sink. After correction of this deformity by cranioplasty, the EEG finding on Nov. 24, 1975 (Fig. 1c), showed great improvement in accordance with her clinical course.

Case 18: 43-year-old female. Primary disease: left sphenoid wing meningioma.

An extensive meningioma from the left sphenoid wing, involving the left middle cerebral artery, was partially removed, and the bone flap not replaced, for decompressive purposes, on Nov. 28, 1974, and a shunt device was inserted for post-operative hydrocephalus in 6 weeks. She was discharged with right hemiparesis, dysphasia and a variety of left parietal lobe signs. Because of gradual deterioration during the 10 months after the primary surgery, she was admitted under suspicion of further growth of tumor. Her large skin flap was flat. Various radiological investigations showed no changes in the size of the residual tumor. Cranial repair alone was performed on Nov. 27, 1975, with results of marked improvement in her dysnomia and weakness, particularly in skillfulness of individual fingers and of foot tapping from the 5 th day after surgery. EEG findings coincided with this clinical course.

Case 19: 51-year-old female. Primary disease: ruptured aneurysm of right middle cerebral artery.

On May 31, 1974, an aneurysm of the right middle cerebral artery was successfully obliterated and the bone flap was removed for the

Table 6 Changes in each EEG abnormality following cranioplasty.

\begin{tabular}{lcccr}
\hline Preoperative Abnormality & Improved & No Changes & Deteriorated & \\
\hline $\begin{array}{l}\text { Dysrhythmia } \\
\text { Slow Abnormality }\end{array} \quad 6$ & 1 & & 7 \\
$\quad$ theta & 5 & 4 & 1 & 10 \\
$\quad$ delta & 5 & 1 & & 6 \\
$\quad$ low voltage slow & & 2 & & \\
$\quad \begin{array}{l}\text { Lazy Activity } \\
\quad \text { alpha }\end{array}$ & 3 & 1 & & \\
$\begin{array}{l}\text { Paroxysmal Abnormality } \\
\quad \text { spike }\end{array}$ & 3 & & \\
$\quad$ sharp wave & 3 & & & 3 \\
$\quad$ spike and wave complex & 1 & & & 1 \\
\hline
\end{tabular}




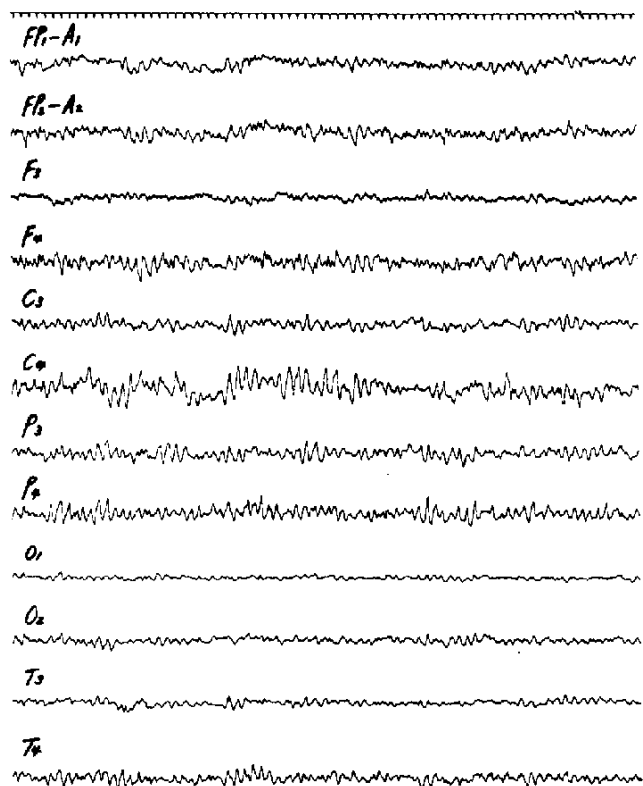

Theoputh son 236

Fig. 1a Tracing 3 months after total removal of right frontal convexity meningioma. Fairly well ordered alpha rhythms were seen bilaterally with higher voltage over the craniectomized area.

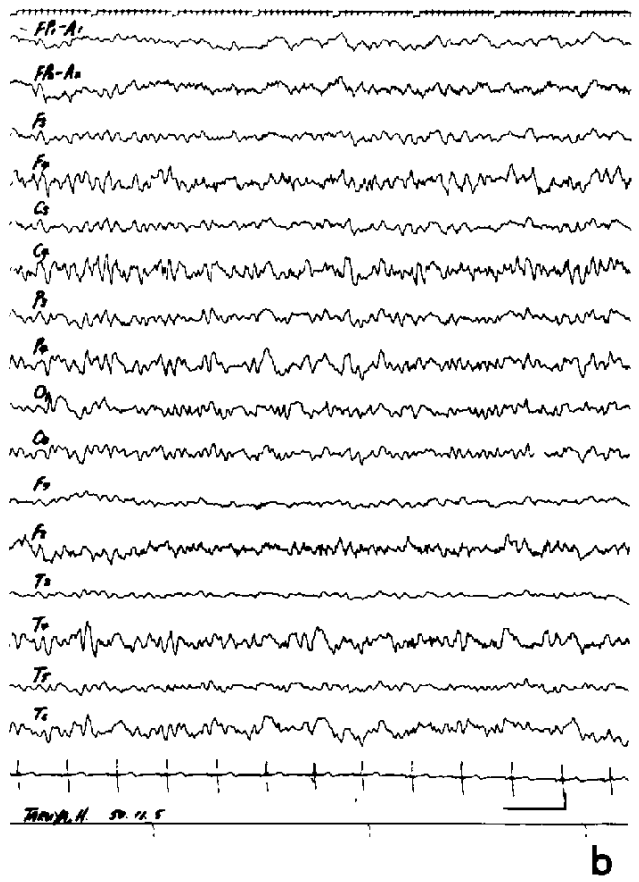

Fig. 1b Tracing before cranioplasty with deterioration of increased slow components more on the concave skin flap. She had noticed clumsiness in her left hand. purpose of external decompression. She was discharged with residual left hemiparesis, sensory deficits and right parietal lobe signs. These neurological deficits persisted with marked concavity of the skin flap. On Dec. 16, 1975, the skin flap deformity was corrected by cranioplasty, followed by remarkable improvement in her neurological status within 3 days. She was then walking without foot-dragging and fine finger motion was much better. Initially low CSF pressure of $50 \mathrm{mmH}_{2} \mathrm{O}$ rose up to $100 \mathrm{mmH}_{2} \mathrm{O}$ after cranial repair and total protein remained within normal limits (Table 4). High amplitude delta activitiies in EEG greatly diminished and alpha rhythms appeared over the right hemisphere postoperatively (Fig. 2a, 2b).

\section{Discussion}

With concavity of the skin flap following decompressive craniectomy, there would be no question about the presence of deformity in the underlying brain tissue. This marked deformity is apparent in pneumoencephalography (Fig. 3)

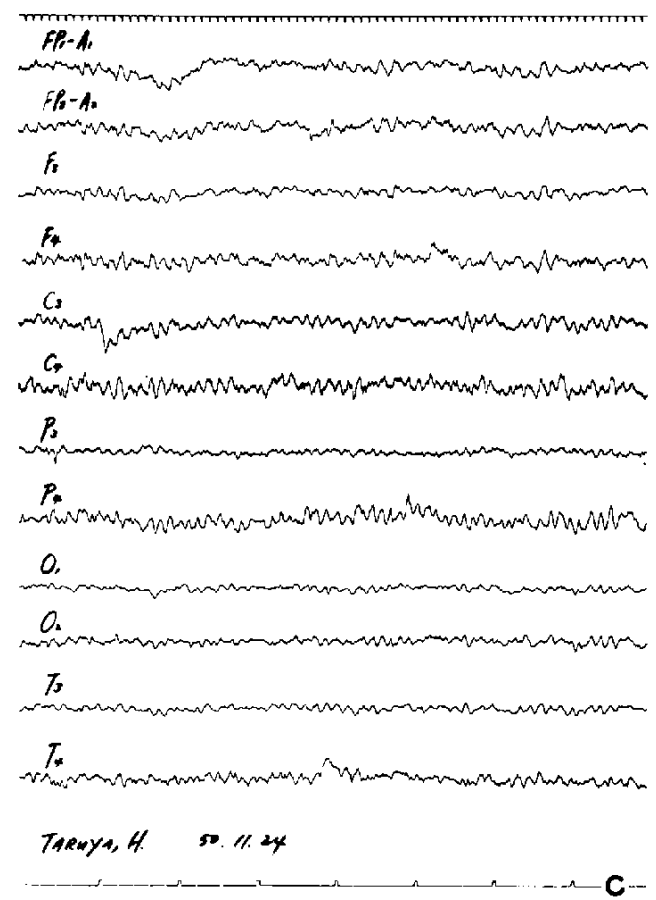

Fig. 1c Tracing after cranioplasty with improvement; clumsiness cleared up.

Fig. 1 Serial observation of EEG in Case 17. 


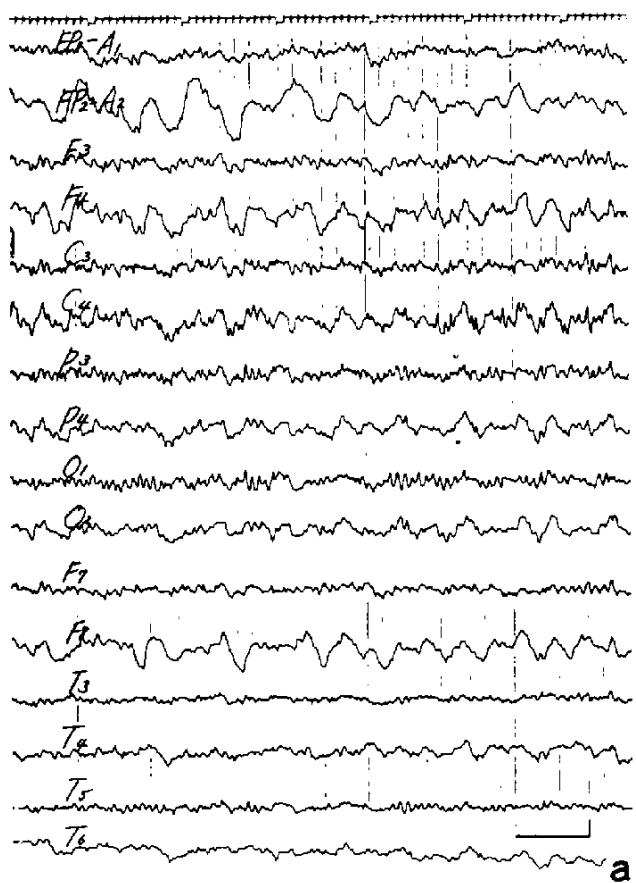

Fig. 2a Tracing, 18 months after the primary surgery for a left middle cerebral aneurysm and 11 days before cranioplasty, showed high amplitude delta activities over the craniectomized area.

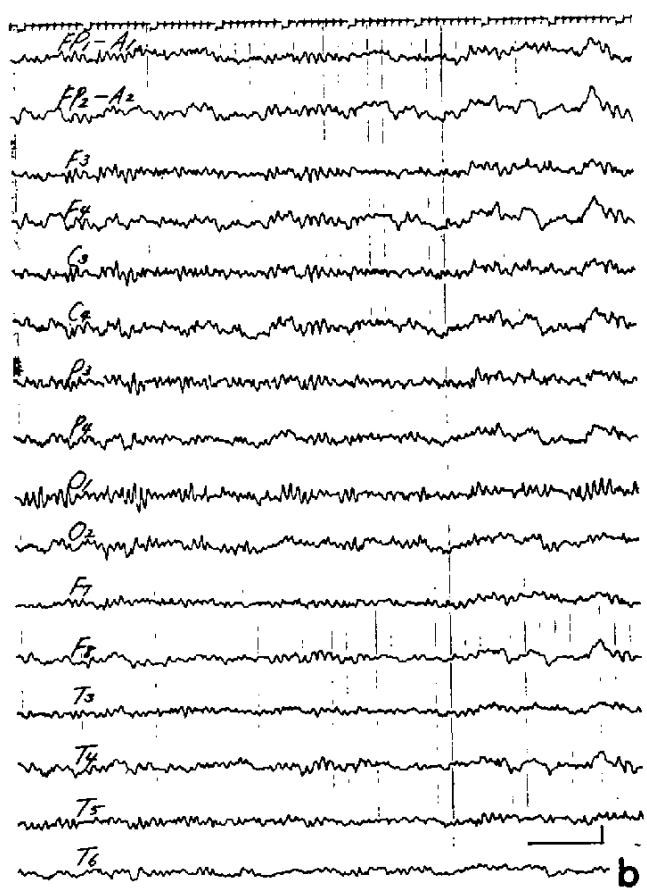

Fig. 2b Tracing on the 22nd day after cranioplasty showed much diminished slow abnormalities and appearance of alpha rhythms. Neurological changes coincided with the above findings.

Fig. 2 Serial observation of EEG in Case 19.

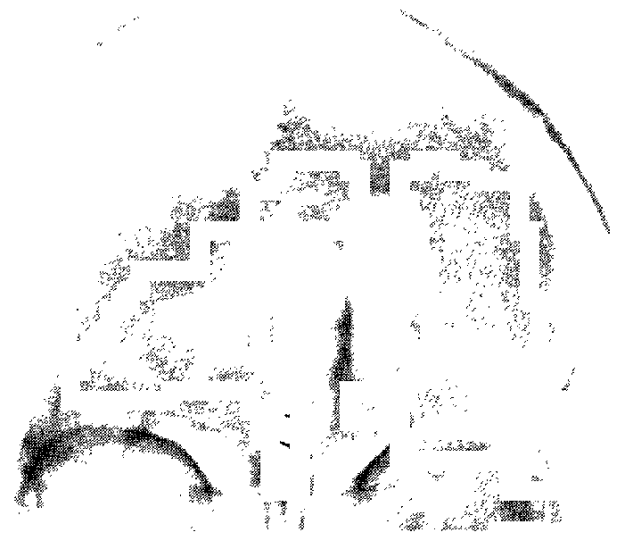

Fig. 3 Pneumoencephalography, on a 65-year-old man after decompressive craniectomy for cerebral contusion and intracranial hematomas, revealed marked displacement of intracranial structure under a sinking skin flap. Not included in this series. 


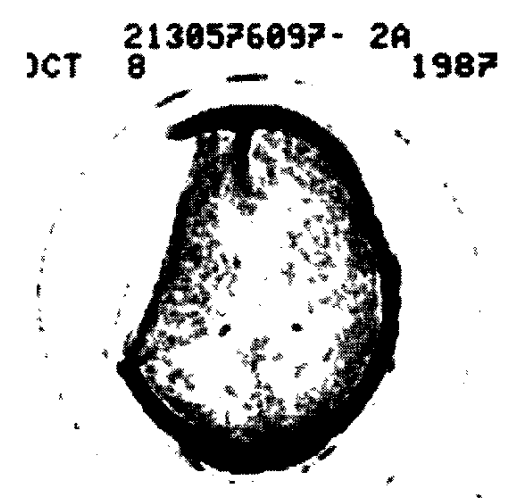

CHIBA UNIY" HQSPIT^

Fig. 4 Computerized tomography, on a craniectomized patient with sinking skin flap; shows remarkable distortion of the brain tissue and ventricular system under the concave skin flap. A 59year-old male, 10 months after surgery on left temporal lobe abscess. Not included in this series.

and computerized tomography (Fig. 4) when performed, and appearance of neurological deficits or deterioration in EEG would be definite evidence of unfavorable effects on cerebral function. Correction of such deformity of the skin flap and the underlying brain tissue would be expected to improve neurological status.

To our knowledge, there had been no reports dealing with this phenomenon in relation to deformity of the skin flap until our first report. ${ }^{71}$ A 48-year-old male, a college faculty member, underwent right craniotomy for massive subdural hematoma on Jan. 20, 1969. The bone flap had to be removed subsequently because of postoperative complications. Three months after surgery, he noticed weakness of the left upper extremity starting from fingers with concavity of the skin flap. On May 20, 1969, cranioplasty was performed using the preserved autogenous bone flap, followed by gradual improvement of the neurological deficits. He eventually returned to his previous occupation. In July, 1970, the skin flap began to sink again, accompanied by the same neurological deterioration. On Sept. 2, 1970, the atrophied and sunken bone flap was removed and a methyl metacrylate plate was molded. This procedure was followed by prompt neurological improvement on the 6th postoperative day. His repeated episodes coincided with EEG changes.

Following this interesting case, 100 cases of cranioplasty with detailed records after large decompressive craniectomy were selected for analysis of this phenomenon. ${ }^{9)}$ Fifty two of them had neurological deficits and 4 out of the 52 showed prompt improvement of their longstanding deficits following the cranial repair. It was noteworthy that all of these 4 patients had sinking or flat skin flap while none of the 13 cases with full or bulging skin flap improved. Correction of such deformity of the skin flap and the underlying brain tissue was considered to be responsible for this favorable result.

Considering that the above observation were only retrospective analysis, the present study was conducted in 33 consecutive cases in order to know the true incidences of such a phenomenon. Confirmed here again was the fact that the cranial repair in the presence of sinking skin flap deformity had resulted in definite improvement in the neurological status. Further analysis revealed that the best results would be expected in those patients with neurological deficits of not too light or not too serious grade. Such "candidates" were seen more frequently among those with meningioma as the primary disease, in the group with the longer time elapse from the decompressive craniectomy or in the presence of the shunt system. The latter two factors might have caused more marked concavity of the skin flap and the underlying brain tissue.

CSF pressure, measured in this manner, would reflect the height of the column of CSF above the reference point. In such a situation where the skin flap and the underlying brain tissue are sinking under the pressure of the atmosphere, CSF pressure would inevitably measure low. Low CSF pressure itself does not seem to have unfavorable effects on cerebral function, as pointed out by Northfield. ${ }^{4 \prime}$ Drainage of CSF in experimental animals with closed cranial cavity did not cause any significant changes in EEG and vital signs. ${ }^{11}$ It is the deformity of the intracranial structure, with or without impaired blood circulation in cerebral vasculature, under a concave skin flap resulting from pressure difference between the extra- and intracranial spaces that causes deterioration in neurological status and in EEG, and this is 
corrected by cranioplasty to improve neurological status. Normalization of CSF pressure after cranial repair would suggest reforming of the intracranial structure, including the ventricular system and the subarachnoid space over the convexity. Recently introduced computerized tomography has eloquently visualized distortion of the ventricular system and the brain tissue (Fig. 4). The mechanism of persistent low CSF pressure with increased total protein in disabled patients is not fully understood, but the presence of obstruction in the CSF pathway, probably due to arachnoid adhesion of various causes, would be one of the possibilities.

EEG may be routinely taken before and after the cranial repair over a varying time period. However, no discussion has been devoted to the relation to the concave deformity over the large cranial defect. Spence ${ }^{s \prime}$ suggested methyl metacrylate plates would be approximately as resistent to EEG as skull structure of the same thickness and regarded the presence of epilepsy as one of the indications for cranioplasty. Disappearance of paroxysmal abnormalities was striking in our study. Serial observation of EEG offered strong evidence of reversible mechanism in clinical deterioration from concavity of the skin flap and the brain tissue, and of the favorable effects of correction of such deformity by cranioplasty. In our method, EEG study cannot be used to predict clinical improvement, because in many patients neurological improvement appeared so promptly within several hours to days after the cranial repair that opportunity was not provided for EEG study until removal of stitches.

Woolf and Walker ${ }^{8)}$ stated that there appeared to be no indication for cranioplasty in an individual suffering from a severe disability such as hemiplegia. From our experience, this is not true in the presence of concave deformity of the skin flap.

Grantham and Landis, ${ }^{2)}$ from analysis of a collection of 100 cases, concluded that the chief value in cranioplasty lies in the repair of a cosmetic defect, if one exists, or in the elimination of psychological factors that result from the presence of the skull defect. As a matter of incidental interest, they were impressed with one outstanding fact, namely that almost every partially aphasic patient became able to use more words after cranioplasty and one patient who was able to use only 10 words before cranioplasty became able to use 190 words within a week postoperatively. However, they gave no reason for this unusual improvement and did not mention the state of the skin flap over the skull defect. It is our experience that the nature of the neurological deficits which showed improvement after cranioplasty comprised a variety of objective abnormalities including dysphasia, weakness, particularly in the distal part of the limb, other parietal lobe signs, and homonymous hemianopsia. In one case, the homonymous hemianopsia following surgery for tentorial meningioma and shunt procudure improved after correction of significant concavity over the right occipital area. Considering that neurological deterioration may be due solely to concavity of the skin flap and the underlying brain tissue under pressure of the atmosphere, this characteristic phenomenon might be described as "the syndrome of the sinking skin flap."

This phenomenon, "the syndrome of the sinking skin flap," should not be confused with the so-called 'syndrome of the trephined' or 'the post-traumatic syndrome,' which are mainly related to subjective complaints with significant psychic or neurotic components, excepting the presence of headache. ${ }^{2)}$ There is unanimous agreement that the post-traumatic syndrome can neither be proved nor denied by any kind of EEG and a great number of normal tracings were manifested in these patients. ${ }^{1}$ In this study, subjective improvement after cranioplasty was not considered insofar as it was not confirmed by objective examination.

In 1976, there appeared a single case report of exactly the same clinical picture. ${ }^{6}$ Tabaddor and LaMorgese presented a case of neurological deterioration with concave skin flap after decompressive hemicraniectomy which recovered promptly following cranioplasty. They claimed this to be the first such report, which was responded to by a short report from our experiences. ${ }^{10)}$

Two cases of Guido and Patterson, Jr. were of a quite similar phenomenon, caused by concavity of the skin flap due to CSF leakage after lumbar puncture and treated by epidural blood patch. ${ }^{3 \prime}$

In conclusion, neurological deterioration was 
caused by concavity of the skin flap following large decompressive craniectomy and this was reversed by correction of the deformity. The responsible mechanism of deterioration would be distortion of the underlying brain tissue, exposed to the pressure of the atmosphere through a skin flap, and the cranioplasty corrected the pathological process, resulting in neurological improvement. This characteristic phenomenon might be discribed as "the syndrome of the sinking skin flap."

\section{References}

1) Courjon, J.: Post-traumatic syndrome. In, Remond, A. (editor-in-chief): Handbook of Electroencephalography and Clinical Neurophysiology, Elsevier Publishing Company, Amsterdam, The Netherlands, 1972, pp. 14B-66-67

2) Grantham, E. G. and Landis, H. P.: Cranioplasty and the post-traumatic syndrome. $J$. Neurosurg. 5: 19-22, 1948

3) Guido, L. J. and Patterson, Jr., R. H.: Focal neurological deficits secondary to intraoperative CSF drainage: Successful resolution with an epidural blood patch. Report of two cases. $J$. Neurosurg. 45: 348-351, 1976

4) Northfield, D. W. C.: "The Surgery of the Central Nervous System," 1st Ed., Blackwell Scientific Publications, Oxford, London, Edinburgh, Melbourne, 1973, pp. 9-11

5) Spence, W. T.: Form-fitting plastic cranioplasty. J. Neurosurg. 11: 219-225, 1954

6) Tabaddor, K. and LaMorgese, J.: Complication of a large cranial defect. Case report. J. Neurosurg. 44: 506-508, 1976

7) Uemura, K., Yamaura, A and Makino, H.: The syndrome of intracranial hypotension. Traumatology (Tokyo) 6: 387-392, 1975

8) Woolf, J. I. and Wakler, A. E.: Cranioplasty. Collective Review. Int. Abst., 81: 1-23, 1945

9) Yamaura, A., Sato, M., Meguro, K., Nakamura, T., Uemura, $K$. and Makino, H.: Cranioplasty following decompressive craniectomy. Analysis of 300 cases. Presented at the 34th Annual Meeting of the Japan Neurosurgical Society, Oct., 1975, Neurological Surgery (Tokyo) 5: 345-353, 1977

10) Yamaura, A. and Makino, H.: Neurological deficits following craniectomy. J. Neurosurg. 45: 362, 1976 (Neurosurgical Forum)

11) Yamaura, A. and Nakamura, T.: unpublished data 